
wave. Young Communist women in Uruguay 60s, Revista Izquierdas, número 22, enero 2015, ISSN 07185049, Santiago de Chile, pp.204-226

\title{
La otra nueva ola Jóvenes mujeres comunistas en el Uruguay de los 60
}

\author{
The other new wave \\ Young Communist women in Uruguay 60s
}

Ana Laura de Giorgi*

\begin{abstract}
Resumen
Este artículo analiza la experiencia de las mujeres comunistas en su calidad de jóvenes, estudiantes y militantes en los sesenta. Esto implica comprender tanto los alcances de la revolución sexual y cultural como los efectos de la militancia política en sus trayectorias personales, determinadas tanto por su colectivo de pertenencia como por su clase social. Como se verá en el recorrido de esta propuesta, a pesar de ser coetáneos, estos fenómenos no interpelaron de igual modo a las jóvenes comunistas ni produjeron los mismos efectos en la transgresión a los mandatos de género.
\end{abstract}

Palabras clave: mujeres, jóvenes, comunistas, revolución política, revolución sexual, cultura juvenil.

\begin{abstract}
This paper focuses on the experience of young communist women who were both students and political activists in the sixties. With this in mind, it inquires into the impact of activism, sexual revolution, and cultural change on their personal histories, and on the ways they were shaped both by their party affiliation and by their class origins. Even though these women all experienced the sixties, the phenomena on which the paper focuses did not impact all young communist women equally, and had different implications for the ways and the degree to which they transgressed gender roles.
\end{abstract}

Keywords: women, young, communist, political revolution, sexual revolution, cultural youth.

\footnotetext{
* Uruguaya, docente e investigadora del Instituto de Ciencia Política de la Facultad de Ciencias Sociales, Universidad de la República -UdelaR-, analauradegiorgi@gmail.com.
} 
Ana Laura de Giorgi, La otra nueva olaJóvenes mujeres comunistas en el Uruguay de los 60 / The other new wave. Young Communist women in Uruguay 60s, Revista Izquierdas, número 22, enero 2015, ISSN 07185049, Santiago de Chile, pp.204-226

\section{Introducción}

Durante la última década del siglo XX y la primera del siglo XXI, han proliferado en el Conosur las investigaciones ancladas en el campo de la Historia Reciente. Estos estudios se han abocado a los años sesenta y setenta, época que transporta al lector a un tiempo de revolución política, social y cultural. El dinamismo de este campo de estudios ha permitido contar con perspectivas novedosas a la hora de interpretar el pasado reciente, aunque en modo alguno los 60 y 70 han sido comprendidos de forma exhaustiva.

En Uruguay, los primeros estudios se centraron en las organizaciones políticas que fueron protagonistas de la época: las organizaciones de izquierda y dentro de este universo las agrupaciones armadas (Aldrighi 2009; Garcé 2006; Gatto 2004; Labrousse 2009; Lessa 2002; Rey Tristán 2006). De forma paulatina fueron surgiendo nuevas investigaciones que buscaron focalizar la atención no tanto en las organizaciones sino en los sujetos políticos que habitaban en ellas (De Giorgi 2011; Graña 2011; Silva 2009; Markarian 2012). Estos trabajos permitieron inscribir las experiencias intersubjetivas de algunos de sus protagonistas y comprender desde una nueva perspectiva las profundas transformaciones de la época. En el contexto de esta nueva literatura fue posible visibilizar un nuevo sujeto: las mujeres, que pasaron a ser las protagonistas de una serie de investigaciones producidas en Argentina y contestaron el androcentrismo que había caracterizado a los análisis sobre la militancia política. A pesar de lo novedoso de estos enfoques, también en esta literatura la atención se focalizó en las experiencias en las organizaciones armadas (Andújar et al 2005; Diana 2006; Martínez 2009). En este sentido cuando miramos los sesenta y setenta contamos con un relato muy anclado en las organizaciones políticas, principalmente las organizaciones armadas, y en sus protagonistas, principalmente los varones.

Por otra parte, investigaciones realizadas en Argentina y ancladas en otro registro como aquel de las transformaciones socioculturales y su interpelación directa a las mujeres (Cosse et al 2010; Andújar et al 2009; Cosse 2010; Felitti 2012), permitieron comprender la generalidad del fenómeno de la revolución sexual y cultural que trascendió las experiencias militantes. En estos casos pudimos conocer otros sesenta y setenta, aquellos de la cultura juvenil, de los medios de comunicación, los Beattles y la pastilla anticonceptiva, que para el caso de las mujeres se tornaron fenómenos trascendentes a la hora de comprender la distancia que algunas jóvenes tomaron respecto a la trayectoria de sus madres.

En Uruguay el desarrollo de este tipo de investigaciones fue mucho menor y varios abordajes quedaron pendientes: el análisis de la experiencia militante de las mujeres en las organizaciones políticas -fueran armadas o no-, el estudio de las transformaciones de los mandatos de género y la comprensión de los alcances de la revolución cultural y sexual. El objetivo de este artículo es realizar un aporte a partir del análisis de la experiencia de las mujeres comunistas en su calidad de jóvenes y militantes en los sesenta. Esto implica comprender tanto los alcances de la revolución sexual y cultural como los efectos de la militancia política en sus trayectorias personales. Como se verá en el recorrido de esta propuesta, a pesar de ser coetáneas, la revolución sexual y la política no interpelaba en los mismos sentidos ni convocaba con igual éxito a todos los tipos de públicos. Sin embargo se consideran aspectos claves que hay que analizar de forma interrelacionada para comprender las trayectorias de las militantes. Esto implica partir de una concepción amplia de lo 
Ana Laura de Giorgi, La otra nueva olaJóvenes mujeres comunistas en el Uruguay de los 60 / The other new wave. Young Communist women in Uruguay 60s, Revista Izquierdas, número 22, enero 2015, ISSN 07185049, Santiago de Chile, pp.204-226

político donde lo cultural es parte constitutiva y donde lo personal es otro terreno de disputa y batalla cotidiana. En este sentido se buscó trascender la clásica división analítica de lo público y lo privado que ha persistido a la hora de analizar los sesenta y registrar prácticas y discursos que hacían a lo que suele denominarse "vida privada" considerándolas como aspectos sustantivos de una experiencia política.

El impacto de las transformaciones políticas, sociales y culturales en las jóvenes que se volcaron al espacio público en los sesenta es un tema de enorme complejidad. Su abordaje completo requeriría de una investigación profunda que abarcara un amplio espectro de experiencias militantes. No obstante, la propuesta de análisis aquí presentada se concentra en un grupo específico con el objetivo de reconstruir una experiencia particular y abordarla en su mayor complejidad. Para ello, deben ser realizadas varias precisiones a la hora de justificar este objeto de estudio y esta mirada anclada en las mujeres.

Respecto a lo primero, este estudio pretende revisar la militancia, no en la izquierda armada sino en la izquierda legal para comprender cómo dichas experiencias se inscribieron en contextos distintos. Dentro de la izquierda legal, optamos por analizar una de las organizaciones de mayor protagonismo en los sesenta y principal opositora de la izquierda armada, como era el Partido Comunista del Uruguay (PCU). Esto implica considerar la experiencia militante de las mujeres dentro del PCU, y a su vez la del partido dentro del contexto político local, buscando comprender cómo se construyeron esas trayectorias "micropolíticas" sin desentenderse de las "macropolíticas" (Cernadas y Tarcus, 1997).

El colectivo comunista de los sesenta, conformado por el partido y su juventud, era amplio y diverso. Una organización-que según cifras oficiales, alcanzó los 50.000 afiliados y alojaba a una heterogeneidad importante de militantes. Este artículo no analiza la experiencia de todas las mujeres, sino sólo de un grupo: el de las jóvenes estudiantes de fines de los sesenta. Esto implica que quedan fuera de este estudio, y pendiente para futuros trabajos, las experiencias extremadamente ricas de las obreras, las intelectuales, las maestras, las esposas de los dirigentes y otros agrupamientos analíticos que pudieran realizarse.

En segundo término, es necesario realizar una justificación más compleja: el análisis a partir de la experiencia de "las mujeres". Esta no ha sido una decisión sencilla sobre todo por los riesgos que conlleva de reproducir una mirada de corte esencialista. Sin embargo, esta propuesta analiza la trayectoria de las mujeres porque sin dudas ella fueron las más interpeladas por una revolución política y fundamentalmente por la "revolución sexual". Esta última, una revolución heterosexual que interpeló directamente a las mujeres y que les permitió, a ellas fundamentalmente, transgredir los mandatos de género vigentes. Siempre dentro de un marco de heteronormatividad es que se fue modificando el campo de posibilidades. Algunas fueron directamente beneficiadas, mientras otr@s continuaron en una situación de subordinación a pesar de todos los proyectos emancipatorios políticos y sexuales que esta época supuestamente ofrecía (Sempol, 2010). Los resultados de este trabajo, aun centrados en los testimonios de las mujeres, permiten apreciar los límites de la revolución sexual y política como promotora de una emancipación para quienes no se sentían convocados por los marcos heterosexuales. Parece más que pertinente recordar en este aspecto el tan acertado señalamiento de Michelle Foucault (1995) sobre las formas del poder: El poder no está determinado solamente por las prohibiciones sino mucho más por 
Ana Laura de Giorgi, La otra nueva olaJóvenes mujeres comunistas en el Uruguay de los 60 / The other new wave. Young Communist women in Uruguay 60s, Revista Izquierdas, número 22, enero 2015, ISSN 07185049, Santiago de Chile, pp.204-226

las incitaciones y lo que define el límite entre lo permitido y lo prohibido, entre "lo normal" y el "desvío",

El universo aquí estudiado es pequeño, pero no por eso menos complejo sino todo lo contrario. La condición de jóvenes mujeres estudiantes militantes, conduce a contemplar los estudios anclados en la juventud y la cultura juvenil; los análisis de género; las investigaciones sobre la modernización y las clases medias y los estudios sobre la militancia política en los sesenta. La experiencia de las jóvenes comunistas estuvo atravesada por distintos factores de mediano y largo alcance así como por aspectos que hacían a su inscripción política o la trascendían. En este sentido la incorporación de una mirada atenta a la clase social de pertenencia resultó fundamental. No todas las jóvenes mujeres comunistas de fines del sesenta, experimentaron la emancipación sexual y política en los mismos términos. Luego de tantos desarrollos y discusiones dentro de la literatura feminista, no deberíamos cometer el común error de considerar y analizar la subordinación de género -o su contestación- de forma aislada a los condicionamientos socioeconómicos. Otros estudios de mayor porte han señalado como la revolución sexual y cultural tuvo como protagonista a la clase media (Cosse, 2010). Por tanto resulta imprescindible comprender cómo las distintas batallas culturales y políticas también estuvieron mediadas por una pertenencia de clase.

Este artículo es producto de una investigación que se realizó a partir de fuentes escritas y orales. Las primeras refieren a prensa escrita de la época: el diario El Popular y algunos folletos del Comité Femenino del Frente de Izquierda de Liberación (FIdeL) a nivel nacional, las revistas La Mujer Soviética y Mujeres del Mundo Entero de la FDIM. Las segundas ocupan un lugar central en esta propuesta y son los testimonios de mujeres que en los sesenta eran jóvenes estudiantes montevideanas y pertenecían al colectivo comunista. Los testimonios se relevaron a partir de entrevistas en profundidad a treinta mujeres. La selección de las entrevistas estuvo orientada por ciertos criterios que se consideraban relevantes a los efectos del análisis. Uno de los principales fue la consideración tanto de militantes que provenían de una familia comunista como de quienes ingresaron al colectivo desprovistas de una tradición familiar de pertenencia al PCU. Como se verá más adelante esta distinción será de algún modo significativa. A su vez, aunque la condición de estudiantes de Preparatorios o de la Universidad ya daba cuenta de un perfil socioeconómico, se buscó entrevistar a quienes provenían de una familia obrera como de quienes lo hacían de la clase media intelectual del partido. Las trayectorias inmediatas a la militancia durante la dictadura fue otro de los aspectos considerados y se buscó entrevistar a mujeres que transitaron por la cárcel, que se exiliaron o que permanecieron en el país en condiciones de clandestinidad o desmovilización. Por último, y no menos importante, se buscó dialogar con aquellas comunistas que luego devinieron en feministas.

Este texto se articula en cuatro apartados. En el primero se describe el pasaje al espacio público de las jóvenes comunistas, los mandatos militantes y las transgresiones habilitadas por dicho proceso en sus variantes diferenciadas de acuerdo a las distintas trayectorias familiares de las jóvenes. En el segundo apartado, el centro de atención se ubica en las articulaciones con la cultura juvenil de la época, en los modos distintos de incorporación de este fenómeno de acuerdo al colectivo político y a la clase social de pertenencia. En el tercer apartado el análisis se orienta a la revolución sexual y su interpelación en las jóvenes comunistas, identificando los momentos de transgresión a los 
Ana Laura de Giorgi, La otra nueva olaJóvenes mujeres comunistas en el Uruguay de los 60 / The other new wave. Young Communist women in Uruguay 60s, Revista Izquierdas, número 22, enero 2015, ISSN 07185049, Santiago de Chile, pp.204-226

mandatos de género así como sus límites. Estos dos últimos apartados nos permitirán repensar los distintos modos de transgredir a las pautas de género que tuvieron las jóvenes comunistas de fines de los sesenta en el Uruguay. Así podremos ver cómo tirar piedras en una manifestación, fue tan transgresor como usar minifalda o tomar la pastilla. El último apartado es una breve conclusión que pretende articular la revolución política con la cultural y sexual, analizando las condiciones que habilitaron los distintos recorridos así como sus efectos en términos de representaciones de género. .

\section{Ser joven mujer y militante en los sesenta}

A diferencia de décadas anteriores, en los sesenta, las mujeres no eran minoría en el sistema educativo en Uruguay. La matrícula había crecido exponencialmente y la feminización de la misma había delineado una composición heterogénea -por lo menos en términos de género- de la educación secundaria y terciaria ${ }^{1}$. El ingreso a estos centros educativos traía aparejado para las jóvenes de la época mayores oportunidades para la socialización ${ }^{2}$. Las esquinas, los alrededores y los cafés frente a los liceos ampliaban los espacios para vivir un momento de la vida que no era el de la niñez ni el del mundo adulto y que quedaba al resguardo de la mirada familiar (Manzzano, 2010:370). En Montevideo, luego de culminado el Liceo, las jóvenes ingresaban a Preparatorios, que como lo indica su nombre preparaba durante 2 años el ingreso a la Universidad. Formalmente preparatorios era parte de la Enseñanza Media y quienes se encontraban en este ciclo eran menores de 18 años. Sin embargo, Preparatorios significaba un espacio distinto y de claro pasaje a una juventud más autónoma. Dicha autonomía se reforzaba con el ingreso al mundo de la militancia política, que aunque pudiese haberse producido antes, en la familia o en el primer ciclo, adquiría mayor intensidad al acercar a las estudiantes con la militancia universitaria.

Como señalan Paris y Ruiz (1998:277), en los sesenta pervivía el tipo de familia tradicional con un único proveedor y la madre esposa ocupada del cuidado de los hijos. Esta descripción se adecua en parte a las familias comunistas en las que se criaron las jóvenes de esta investigación, pero sólo en parte y que las madres-esposas, además de ocuparse del hogar, salieron tempranamente a trabajar y tenían voz, muchas veces voto, en la mesa familiar. La autoridad paterna continuaba vigente, pero las madres también ocupaban un rol distinto al ocupado en otras familias tradicionales. En algunos casos incluso, cuando los padres eran funcionarios del partido, el mayor ingreso provenía de las mujeres. En estas familias crecieron muchas de las jóvenes protagonistas del 68 uruguayo, aquellas que tempranamente se socializaron políticamente en un entorno familiar donde la

\footnotetext{
${ }^{1}$ En el quinquenio 1956-1960, unas 130.687 jóvenes mujeres se habían matriculado en los liceos públicos mientra que la cifra para el quinquenio 1966-1970 era de 252.347 estudiantes. (Greising 2012: 358). A nivel terciario la matrícula en Uruguay también había tenido un crecimiento extraordinario. El informe de la CIDE señalaba que el país presentaba una de las tasas de matriculación (por mil habitantes) más altas del mundo y en América Latina la tasa sólo era superada por Argentina.

${ }^{2}$ En Markarian (1998) se puede consultar un análisis sobre la década previa en la que comenzaron a vislumbrarse ciertos signos del protagonismo juvenil.
} 
Ana Laura de Giorgi, La otra nueva olaJóvenes mujeres comunistas en el Uruguay de los 60 / The other new wave. Young Communist women in Uruguay 60s, Revista Izquierdas, número 22, enero 2015, ISSN 07185049, Santiago de Chile, pp.204-226

política era el centro del hogar, donde llegaban diarios y libros de izquierda de forma permanente y en el que todos, incluidas las hijas mujeres, se quedaban hasta tarde en la noche discutiendo sobre política. Los relatos de las jóvenes de familia no comunista sobre sus madres, coinciden mejor con el patrón más tradicional ya que las madres se ocupaban de "tener la comida pronta" y acompañar a sus maridos en las cuestiones políticas. En estos casos la novedad surgía de los padres, los primeros referentes con los que contaron para preguntar y discutir estas noveles interesadas en cuestiones políticas.

Si dentro de las familias comunistas quienes hacían la diferencia eran las madres discutidoras y cuestionadoras, en las familias no comunistas los padres parecen haber cumplido un rol fundamental en el impulso o respaldo a sus hijas hacia un modelo de mujer educada, independiente e interesada en política. En general estos padres eran aquellos identificados con los partidos tradicionales provenientes del ala batllista, anticlericales y liberales, que transmitían cotidianamente en el hogar mensajes que llegaban directamente a los oídos de las hijas en los comentarios más cotidianos y a la vez más significativos, como recuerda Verónica a su padre cuando este le decía "Tu no vayas a tomar una coca cola sino te la vas a poder pagar'. En familias de sectores populares, el esquema volvía a reiterarse y los padres resultaban ser los principales respaldos de las jóvenes militantes, aquellos que se imponían ante la aprehensión de las madres y quienes realizaban tareas de apoyo para que sus hijas participaran. Paula recuerda como su padre la iba a esperar a la parada pasándose horas al frío porque "sabía que de la asamblea no podías irte, que un voto era un voto y había que aguantarlo".

Las familias fueron más que importantes para las trayectorias de las jóvenes porque ellas fueron hijas de una generación que ya manifestaba signos de cambio (Paola Martínez, 2009:44). Sin embargo, la familia, y sus límites, fueron traspasados por las propias jóvenes que de modos distintos comenzaron cada vez más a transgredir ciertos mandatos. Las movilizaciones callejeras, las asambleas estudiantiles tarde en la noche, las ocupaciones de los centros educativos y los campamentos de la juventud comunista, se constituyeron en espacios autonómicos donde las jóvenes comenzaron a conquistar ciertos momentos de libertad fuera del control familiar y de las reglas de la moral vigente. Las primeras entradas al espacio público, es decir la participación en movilizaciones callejeras, para las mujeres implicaba no sólo el riesgo de la represión policial sino también paternal (y patriarcal). Como recuerda Susana, no sólo había que tener coraje para participar de una manifestación estudiantil, sino también para enfrentar la sanción en el hogar: "tenías miedo claro, dos miedos, eso nos pasaba a nosotras, no a los varones, normalmente mentías cuando salías a hacer esas cosas, entonces si me llegaban a agarrar presa, mis padres me mataban y ese era el problema más grande para nosotras". El "problema más grande" era no solo la familia, sino toda la sociedad, incluso sus propios congéneres -varones- que pretendían establecer los límites de los espacios que las jóvenes podías transitar. Lo público era la calle (Markarian 2012:54), un lugar familiar y apropiado por los varones al que las jóvenes querían ingresar pero que no resultaba tan sencillo. Paula relataba cómo su novio la "sacó de la movilización y (la) llevó caminando para abajo unas cuadras", ahí la "dejó", y ella volvió a un lugar que ya estaba vallado y del que se había quedado excluida por su propio novio, por lo que ella sintió "muchísima rabia y ahí fue la tumba de la relación".

Además de participar, caminar y correr en las movilizaciones públicas, un desafío mayor para estas jóvenes fue la adquisición de la voz pública. En estas entrevistas y en 
Ana Laura de Giorgi, La otra nueva olaJóvenes mujeres comunistas en el Uruguay de los 60 / The other new wave. Young Communist women in Uruguay 60s, Revista Izquierdas, número 22, enero 2015, ISSN 07185049, Santiago de Chile, pp.204-226

textos sobre otras experiencias militantes, las mujeres, al día de hoy, recuerdan con exactitud el momento en que se subieron a un banco de liceo, de una mesa o de la escalera de una institución educativa y hablaron al público, porque como señalaba María, esta era una de las pruebas más importantes: "Cuando te parabas arriba de unos bancos y eras capaz de hablar en una asamblea ahí la cosa cambiaba".

Entre la calle y el partido, las jóvenes se fueron socializando políticamente y su inserción estuvo muy marcada por adquirir aquellas cualidades que denotaba el hombre nиеvо у que encarnaban las pautas de la masculinidad vigentes: virilidad, fuerza, valor y coraje. A estas se sumaban las exigencias del propio colectivo comunista: disciplina, sacrificio, capacidad de oratoria y formación teórica (de Giorgi 2011, Silva 2009). Sin embargo, en cualquiera de las versiones - cubana o soviética- del ideal militante, las mujeres se enfrentaban a un modelo distinto y sabían que debían dar pruebas en ese sentido, sin “dejarse amilanar por ser mujer". La idea de una militancia por fuera de estos cánones que se reivindicara desde la diferencia no estaba dentro del campo de posibilidades. El discurso de la igualdad tan fuertemente instalado en la cultura comunista anulaba toda posibilidad de una práctica política que permitiera ver diferencias socioculturales más allá de la contradicción principal. Al igual que el individuo abstracto y la Declaración Universal de los Derechos del Hombre y del Ciudadano permitieron plantear una igualdad formal (Scott 2012), la categoría comunista cumplió una función similar. El individuo abstracto permitió plantear una igualdad fundamental entre los seres humanos a costa de abstraerlos de sus posiciones sociales diferenciadoras. En algún modo también este era el desafío del discurso en el PCU, erigir una figura como la del comunista y abstraerla de sus posiciones sociales diferenciadoras. La categoría comunista era un recurso igualador para intelectuales y obreros, para mujeres y hombres. A Teresa, quien provenía de un hogar en el que se promovía mucho más que en otros la emancipación de la mujer, le costó mucho tiempo comprender los efectos de dicho discurso:

...eso de que éramos todos iguales, no importaba si éramos hombres o mujeres, todos iguales, algo que era muy avanzado para la época pero que escamoteó. Yo me vine a dar cuenta mucho después, un día en terapia, no sé, con cuarenta años, le digo al terapeuta, esas cosas pelotudas, le digo algo así como que éramos iguales, nos trataban a todos iguales éramos iguales, y el terapeuta me dice: 'pero no eran iguales', y yo le digo sí, éramos iguales, y me dice:' no, tu sos mujer y ellos son hombres'. Y yo ya era feminista y digo a la mierda, como me comí esto. Ese democratismo igualador, de toda la cultura reinante, ese democratismo igualador escamoteaba las diferencias de género, todos iguales, todos iguales y yo me lo tragué, me lo tragué.

Las jóvenes no tenían referentes mujeres ni eran convocadas por otras mujeres desde un discurso de la diferencia. En sentido contrario, el discurso vigente en toda la izquierda y también dentro del colectivo comunista era el de la igualdad. Aunque dentro del colectivo había algunas dirigentes mujeres, estas estaban muy alejadas de la experiencia cotidiana militante de las jóvenes ni representaban figuras a seguir. Julia Arévalo era una referente del pasado y en aquel presente, en los sesenta, no era más que una abuela en sentido figurado y también literal ya que algunas nietas eran parte de este colectivo y sus amigas también. Por otra parte, la convocatoria de las mujeres adultas desde el lugar tradicional de 
Ana Laura de Giorgi, La otra nueva olaJóvenes mujeres comunistas en el Uruguay de los 60 / The other new wave. Young Communist women in Uruguay 60s, Revista Izquierdas, número 22, enero 2015, ISSN 07185049, Santiago de Chile, pp.204-226

la mujer podía poner en riesgo cualquier proyecto emancipatorio que las jóvenes deseaban desarrollar. Claramente, si el lugar reservado para la mujer en el partido, era aquel de "la mujer abnegada y callada de todos los combates populares" ${ }^{3}$, esto resultaba poco atractivo para las jóvenes. Ese lugar, el de las mujeres comunistas, no significaba para estas jóvenes una manera de subvertir el orden, sino todo lo contrario como relataba Susana:

eso me dijo mi papá un día que por supuesto estaba en desacuerdo porque yo militaba y me iba para el seccional. Entonces me acuerdo que mi padre un día me dijo: 'bueno, al menos si te vas con los comunistas llegarás a ser como Julia Arevalo, je, y yo no, no, no, de ninguna manera, como ella ni lo sueñes.

Las figuras femeninas que menos convocaban eran las de las esposas de los dirigentes cuando se las visualizaba en la función de esposas exclusivamente. Esto sucedía con Alcira Legaspi, segunda esposa del máximo líder Rodeny Arismendi, quien es recordada como "mujer de", que "estaba para aplaudir al marido" o "alcanzarle las pantuflas", broma que "se decía bajito" y que circulaba en la época de la militancia.

El diario El Popular del PCU, contaba con una sección destinada a la mujer. Sin embargo, las destinatarias no eras las jóvenes militantes sino las mujeres que acompañaban a los militantes del partido en su calidad de amas de casa, esposas y madres. Dicha sección, El Popular para la mujer y el hogar, claramente invocaban un modelo de mujer en el que las jóvenes no se sentían en modo alguno representadas. Este apartado, que salía los domingos, solía contar con un recuadro destinado a presentar noticias políticas sobre encuentro internacionales de mujeres, informes o conmemoraciones del día de la mujer en otros países ${ }^{4}$. El resto de la página estaba destinada a: peinados, moda y costura, salud y belleza, cuidado del hogar, cocina y recetas, crianza de los niños y una especial sección dedicada a profundizar en el "parto sin dolor". Los artículos estaban orientados a brindar consejos de cómo ser una buena esposa, una buena madre y una buena ama de casa.

Los escasos espacios orgánicos existentes no convocaban a las jóvenes militantes como era el caso del Comité Femenino del Fidel, un espacio orgánico que sólo lograba convocar a algunas mujeres adultas, a "esas señoras que iban a los viajes" e integraban una red más amplia denominada la Federación Democrática Internacional de Mujeres (FDIM), que tampoco convocaba a las mujeres jóvenes, ni a través de sus delegadas uruguayas ni por medio de la Revista Mujeres del Mundo Entero ${ }^{5}$.

La representación que de la FDIM se hacían estas jóvenes no lograba en modo alguno convocarlas ya que era visto como un organismo "desmovilizador" y lejano a la principal causa política de la juventud militante -la revolución-. Como señala Susana: "se de cuentos que participaban de las organizaciones internacionales comunistas, esas organizaciones que eran por la paz en España, por la paz en no se dónde, todas eran por la paz”. En el terreno político ninguna quería ocupar el lugar tradicional de mujer y la FDIM implicaba quedarse

3 Irene Pérez, El Popular, 31 de agosto de 1966.

$4 \quad$ Se presentaba la conmemoración del día de la mujer en Cuba o en la URSS pero este día no parece haberse conmemorado en el PCU ni en el Comité Femenino del Fidel.

$5 \quad$ Un estudio específico de esta publicación resulta imprescindible para valorar la adecuación entre la representación de la FDIM que se realizaban las jóvenes mujeres y el aporte concreto que esta organización realizaba en términos de agenda de género. 
excluidas de la historia. Si existían algunas mujeres referentes estas eran las jóvenes compañeras de militancia más aguerridas, más valientes, aquellas que lograban hablar y convencer a las masas, las que iban en la primera línea de las manifestaciones. Las jóvenes querían ser iguales a los varones, ir de pegatina como ellos, hablar fuerte y ser escuchadas, que no las protegieran ni les asignaran un segundo lugar. Teresa resume con extrema claridad este sentimiento:

todos conocíamos eso, era de las grandes organizaciones mundiales, pero nosotros no queríamos eso, eso era de las viejas (...) nosotros queríamos ser el Che Guevara, no eso, queríamos ser igual a los compañeros, no queríamos ser las mujeres, no queríamos ser las mujeres de, eso las mujeres institucionales, eran las viejas que hacían eso, nosotras no queríamos, queríamos ser revolucionarias, armas, lucha clandestina, nuestros modelos eran hombres (...) si vos preguntabas vos a dónde querés ir a la FDIM o a la Sierra Maestra, no yo a la Sierra Maestra ahí está la libertad, allá no.

La generación del 68, varones y mujeres de todas las izquierda políticas hicieron de la Revolución Cubana una referencia fundamental que no precisaba mujeres en tanto tales sino militantes. A su vez en el caso de Uruguay, tampoco había causas locales que convocaran a construir espacios orgánicos en clave femenina ya que el voto para las mujeres había sido aprobado en la década del treinta y junto con otras normas como la del divorcio, habían producido el efecto indirecto de la desmovilización del feminismo (Sapriza y Villamil, 1984:122). En este período "letárgico" en términos de género (Johnson, 2002), el PCU no se enfrentaba a ninguna propuesta que captara la adhesión de las mujeres y amenazara su poder de convocatoria como había sucedido con la discusión del sufragio en otras épocas (Leibner, 2004) y como sucedía en Argentina con la aprobación del voto femenino y la candidatura de Eva Perón (Barrancos 2008, Valobra 2010). A pesar de la política de frentes seguida por el PCU, de acuerdo a las orientaciones de la Internacional Comunista, el partido no impulsó la construcción de espacios orgánicos fuertes dentro del partido ni la conformación de una red extensa que permitiera el diálogo o convocara a mujeres de otras filas partidarias, como sí lo hizo en el caso de los intelectuales, de los trabajadores y de la política hacia el movimiento estudiantil en aras de conservar el predominio ante el auge de la denominada nueva izquierda.

El ingreso al mundo de la militancia política de las jóvenes, en su calidad de jóvenes y militantes implicó transgredir ciertos mandatos de género haciendo lo que hacían los jóvenes varones: hablar en público y discutir abiertamente, correr en una manifestación, pasar la noche en un campamento político o en una ocupación estudiantil, saltar vallas, quemar gomas y tirar piedras. La participación política se realizó a costa de un acercamiento a pautas masculinas y un alejamiento de la femineidad vigente. Sin embargo este fenómeno convivió con otro que promovió cierto proceso emancipatorio en otro registro, la denominada revolución cultural y sexual, y que de algún modo reinscribió a las mujeres en una condición femenina. 
Ana Laura de Giorgi, La otra nueva olaJóvenes mujeres comunistas en el Uruguay de los 60 / The other new wave. Young Communist women in Uruguay 60s, Revista Izquierdas, número 22, enero 2015, ISSN 07185049, Santiago de Chile, pp.204-226

\section{¿La otra nueva ola?}

A principios de los sesenta, la revista argentina Nuestras Mujeres editada por la Unión de Mujeres Argentina (UMA) y liderada por el Partido Comunista Argentino (PCA), presentaba un artículo titulado: "La otra nueva ola". En este artículo se presentaban pequeñas historias de vida de dos jóvenes mujeres y un varón que mostraban ser "Jóvenes dedicados al trabajo y a la lucha sin admitir la evasión por la frivolidad", "jóvenes abnegados y fuertes", "personas serias, responsables y con aspiraciones sencillas", dispuestos a "construir una vida decente, con amor e hijos educados en la bondad". Estas historias ejemplificaban según la nota que existía "otra nueva ola" que enfrentaba a aquella definida por "chicos barbudos y niñas independientes, gente que no hace nada y no piensa en nada" (Nuestras Mujeres, diciembre 1961, pp.21). La nota periodística antes reseñada contraponía dos modelos de jóvenes, aquellos despolitizados e insertos en una cultura juvenil marcada por la industria cultural de la época, y quienes dedicaban su vida a la política regidos por una cultura militante. Sin embargo, resulta complejo considerar estos dos mundos de un modo tan abstracto y aislado, teniendo en cuenta el alcance masivo de los fenómenos culturales y sociales que convocaron a la juventud al centro de la escena.

Si consideramos los antecedentes de la literatura sobre las prácticas militantes de la izquierda armada podríamos coincidir con aquellos dos modelos que la nota antes citada buscaba representar. Los estudios dedicados a analizar la experiencia de la izquierda armada, han señalado cómo se dio una contestación, desde un ascetismo importante, a las nuevas pautas culturales y juveniles denominadas muchas veces por los militantes como "pequeñoburguesas" (Aldrighi 2009; de Giorgi 2011; Martinez 2009; Diana 2006). Este ascetismo y la cultura del pobrismo por ejemplo del MLN-T en Uruguay (de Giorgi 2011) alejaban a sus militantes, aún a aquellos que tenían medios materiales, de los circuitos culturales de consumo y las modas de la época ubicándolos de algún modo en la vanguardia de la contracultura, lo que se veía reforzado con la incorporación de las pautas del mundo adulto en condiciones de militancia clandestina (Martínez, 2009:68). Sin embargo a la hora de revisitar la experiencia de las jóvenes militantes de un partido legal que buscaba acercarse a la sociedad como es el caso del PCU, podemos observar un proceso distinto.

En el caso de la militancia comunista, militar en la juventud comunista implicaba lo que el propio término indica: juventud + comunista. Es decir que aquellos y aquellas jóvenes que transitaban por aquel espacio además de militantes comunistas eran jóvenes y hacían "cosas de jóvenes" como ir de campamento, reunirse en guitarreadas, ir a los bailes, a la playa en grupo, incorporar las nuevas pautas de vestimenta y jugar al pin pon en el propio local central de la UJC. En estos mismos locales se realizaban bailes y fiestas, de tanta concurrencia que recibían la burla del "afíliate y baila" que sentenciaban otras izquierdas. Como señala Leibner (2011:320) las fiestas atraían la atención de nuevos jóvenes a los locales pero además permitía transmitir una imagen de jóvenes no marginados de las pautas de sociabilidad vigentes. A diferencia de lo que puede resultar de cierto imaginario del militante comunista, los y las jóvenes no renunciaron ni pudieron renunciar a la "nueva ola". No sólo bailaron en los locales de la UJC sino que frecuentaron también los espacios más concurridos. Las jóvenes comunistas de clase media, fueron las que pudieron disfrutar de esta nueva cultura juvenil. Y dentro de este grupo, resulta interesante 
Ana Laura de Giorgi, La otra nueva olaJóvenes mujeres comunistas en el Uruguay de los 60 / The other new wave. Young Communist women in Uruguay 60s, Revista Izquierdas, número 22, enero 2015, ISSN 07185049, Santiago de Chile, pp.204-226

la experiencia de quienes provenían de familia comunista, que al contrario de lo que podría indicar el sentido común o el prejuicio, pudieron incorporarse a los circuitos de circulaciones juveniles desde la autonomía o la confianza que habían generado desde su militancia. En estos casos, su disciplina militante, y la ayuda de algunas madres con voz autorizada, les permitía conquistar otros espacios como los de socialización juvenil de la época como ejemplificaba Teresa:

“... pedí para ir a bailar al Drink del Nautico y mi padre quiso prohibírmelo y mi madre dijo 'no, perdón, si ella puede salir de pintada también puede ir a bailar, ¿cuál es la diferencia?' Entonces cada vez que mi padre pretendía prohibirme algo que tenía que ver con mis actividades de adolescente ella siempre decía lo mismo, no, si ella puede ir de pintadas puede ir a militar entonces puede salir a bailar. Si puede salir con compañeros a hacer tal cosa también puede salir con amigos del liceo".

En aquellos casos de familia no comunista, y con familias provenientes de los partidos tradicionales donde los padres resistían la opción política de sus hijas, las jóvenes también podían disfrutar de los nuevos espacios de socialización y las nuevas pautas de la cultura juvenil. En estos casos muchas veces eran los propios padres, más liberales que las madres, quienes instaban a que las hijas tuvieran una "vida normal" como las otras jóvenes y no quedaran circunscriptas exclusivamente al mundo comunista y por ejemplo sólo a los bailes de la UJC.En cualquier caso las jóvenes salían de noche y la diferencia entre asistir a un baile o a una peña no radicaba tanto en la filiación comunista sino en la extracción de clase social. Para aquellas jóvenes provenientes de sectores populares, preferían las peñas y guitarreadas a los bailes ${ }^{6}$ en las que no se sentían convocadas, como señala Silvia:

...bailes no sé, hacíamos más que nada guitarreadas, íbamos al cine y luego como a la casa de alguien, si había alguien liberado que viva solo o los padres eran geniales y no estaban, porque bailar se iba a una boite y nosotros no íbamos a boites.

La cultura juvenil generaba cierta comunidad de sentido y permitía a quienes pertenecían a una clase media ser parte de nuevas pautas culturales más allá de sus adscripciones políticas. La pertenencia a un estrato social era lo que permitía a algunas jóvenes comunistas ir a bailar a Zum-Zum, a los bailes del Nauthilusss o a los drinks del Naútico, más allá de las críticas y la posibilidad de recibir el apelativo de "burguesitas". Estos gustos distintos claramente dependían de condiciones materiales ya que para frecuentar aquellos espacios se necesitaba contar con los recursos para cubrir el traslado, abonar la entrada y vestirse a la moda, esto último un detalle no menor para la época porque como recuerda Paula "se daba aquello de que te tenías que vestir", aunque comprarse uno de los montgomery que vendían en Adam's o un Levis, símbolos ineludibles de la cultura juvenil de la época no era algo nada accesible.

$6 \quad$ La Boite Zum Zum de Montevideo, al igual que la bonaerense, concentraba gran parte de la movida juvenil en los setenta. Esta boite fue atacada por el MLN-T, considerada el centro de diversión pequeñoburgués 
Ana Laura de Giorgi, La otra nueva olaJóvenes mujeres comunistas en el Uruguay de los 60 / The other new wave. Young Communist women in Uruguay 60s, Revista Izquierdas, número 22, enero 2015, ISSN 07185049, Santiago de Chile, pp.204-226

El fenómeno de la moda definía a toda la cultura juvenil, pero posiblemente las jóvenes mujeres recibían mejores recompensas simbólicas al poder establecer diferencias importantes con sus madres o sus tías. La vestimenta definió uno nuevo terreno de disputa con el mundo adulto y a su vez entre la propia juventud (Manzzano (2010:373). Los vaqueros permitieron a los varones romper con el rito de paso a la adultez a través de los pantalones largos y ubicarse en una situación que no era la del adulto y tampoco la del niño (Manzzano, 2010:378). Por su parte, la minifalda o la pollera tableada kilt produjeron efectos similares en las jóvenes mujeres, para las cuales "dejar de usar soquetes como una nena y pasar a la kilt" fue toda una revolución como recordaba Silvia. La moda femenina que introdujo los vestidos cortos, la minifalda, el bikini, los Oxford, las carteras largas y cruzadas, entre otros elementos, permitió cierta intervención en los cuerpos a la vez que la producción de una nueva imagen de femineidad juvenil. Las jóvenes, relata Silvia, dejaron de usar "esos batidos espantosos" -como los de sus madres- y comenzaron a usar el pelo largo y suelto, "cuánto más largo mejor". Los padres se opusieron a la minifalda, pero todas dieron la batalla por usarla. Las polleras largas fueron abandonadas por la minifalda o los pantalones, los cuales servían tanto para mostrar de un modo diferente el cuerpo como para "correr, saltar bancos y salir volando cuando te corrían". En el cuerpo se inscribió la juventud, la resistencia y también una nueva femineidad, que les permitía a las jóvenes mostrarse de un modo distinto al de las mujeres adultas.

En el caso de las juventudes políticas de izquierda, las posibilidades de incorporar o contestar las pautas de la nueva cultura juvenil de la época estaban atravesadas no sólo por las condiciones socioeconómicas que determinaban consumos y gustos, sino por los códigos del colectivo de pertenencia. A diferencia de lo que puede haber sucedido en el MLN-T, en el que la austeridad se transformó en un criterio rector (de Giorgi, 2011) y homogeneizó estilos de vida, la juventud comunista se desplegó como un espacio atravesado por las pautas socio-culturales de fines de los sesenta. Los y las jóvenes transitaban por distintos espacios, desde el local partidario y las peñas a los bailes de moda. Quienes frecuentaron bailes como los realizados en las boites, también asistieron a lugares como Zum Zum, sindicados por la izquierda armada como el centro de diversión de la juventud burguesa ${ }^{7}$ y como ya vimos incorporaron moda y peinado como distinciones generacionales. Esto sucedía en un colectivo como era el comunista, inserto en la sociedad y por tanto en los patrones culturales de la época reproducidos a través de una importantísima cantidad de estudiantes comunistas que transportaban gustos, modas y clase, lo que conducía a que, como recuerda Margarita “"'te dieras cuenta de diferencias, porque entrabas en el local de la juventud y había una diferencia entre las que venían del Iava (el instituto de formación docente) y la gente que venía de los seccionales del barrio".

Las pautas más o menos homogeneizantes impactaban en una mayor o menor masculinización, al menos en términos visuales, porque claramente y como ya mencionamos la imagen del Che Guevara se extendía por todos los colectivos. Todas querían ser como el líder revolucionario, pero no tenían porqué vestirse como él. En este

\footnotetext{
${ }^{7}$ En Zum Zum, el MLN-T colocó una bomba en el marco del Plan Cacao que apuntaba a desplegar acciones en espacios de la nueva cultura juvenil ("burguesa") que se pretendía desterrar, como las boites o el bowling (de Giorgi 2011:137)
} 
sentido una UJC permeable a las pautas culturales de la época habilitó la reproducción de diferencias socio-culturales pero bloqueó algunas pautas de la homogeneización en clave masculina. El relato del cambio de vestuario de una militante para poder ingresar a una organización armada en Mujeres Guerrilleras, podría ejemplificar cómo las jóvenes se adaptaban a las pautas de los colectivos políticos a los que pretendían ingresar. Pola, entrevistada de Marta Diana, relata su primer contacto fallido con la organización a la que se integraría y su segundo contacto exitoso. Al primero Pola llegó "con diecisiete años, largo pelo lacio hasta la cintura, diminuta minifalda, blusa escotada y un corazón que latía emocionado por la inminencia del encuentro con el "responsable". La interrogaron sobre sus lecturas, observaron detenidamente su atuendo y le prometieron un segundo contacto para más adelante. Esta segunda oportunidad no fue desaprovechada: Pola llegó al bar con "el pelo corto como hombre, zapatillas, blue jeans y camisa de hombre", lo que le garantizó el ingreso buscado (Diana, 1996:90).

\section{Una revolución sexual discreta}

El fenómeno de la cultura juvenil de los sesenta y setenta, alojó a su vez a un fenómeno que alteró las interrelaciones entre los jóvenes como fue el de la revolución sexual. Como ha estudiado atentamente Isabella Cosse (2010), los patrones valorativos y las prácticas en relación a la pareja, la sexualidad y la familia, se fueron transformando paulatinamente en estos años. Las jóvenes comunistas tampoco quedaron al margen de este fenómeno y con modulaciones, todas experimentaron el noviazgo, la sexualidad, el matrimonio y la maternidad, de un modo distinto al que lo habían hecho sus madres.

Como señala Cosse (2010) una de las principales transformaciones en este terreno fue una nueva concepción de los noviazgos, no entendidos estos como la antesala del matrimonio sino como etapas intermedias por las que podían pasar los y las jóvenes. La pauta del cortejo o de las salidas a escondidas, relatada en La Margarita de Rosencof, había quedado abandonada tiempo atrás y las jóvenes podían disfrutar de los noviazgos con mayor libertad que las generaciones precedentes. La multiplicación de los espacios de socialización facilitó las condiciones para hacer y deshacer noviazgos y en los casos de la militancia política las oportunidades se incrementaron aún más, como recuerda María:

Había un roce, que lo daba el propio partido, que hacía que convivieran hombres y mujeres en ámbitos muy propicios para tener intercambios de otro tipo, porque si vos tenías una pegatina, luego la gente se iba junta, una proximidad que te daba todo eso.

En el marco de una relación de noviazgo, y no fuera de ella, las jóvenes transgredieron la norma del mandato virginal para las mujeres. Las relaciones sexuales prematrimoniales habían sido aceptadas por las jóvenes y ninguna pretendía casarse virgen, una pauta de comportamiento que consideraban anacrónica y que dentro de la militancia política había sido desterrada, como explicaba Susana: "Si te arreglabas con un compañero estaba fuera de discusión que te ibas a acostar con él". Los espacios de militancia generaban en este sentido espacios de oportunidad para ir corriendo algunas fronteras 
Ana Laura de Giorgi, La otra nueva olaJóvenes mujeres comunistas en el Uruguay de los 60 / The other new wave. Young Communist women in Uruguay 60s, Revista Izquierdas, número 22, enero 2015, ISSN 07185049, Santiago de Chile, pp.204-226

morales. Sin embargo, a pesar de transgresiones y revolución sexual, los límites existían y en estos casos no eran tan definidos por la familia, sino por el colectivo de pertenencia.

$\mathrm{Si}$ bien algunas jóvenes transitaban por otros espacios de socialización que trascendían el colectivo comunista, los novios pertenecían al ámbito de la militancia política y casi sin excepción al de la UJC. En este terreno, la libertad no era absoluta en la medida que establecer una relación con alguien que estuviera por fuera del colectivo o que no se considerara adecuado podía traer aparejada una intervención desde las jerarquías de la organización. Estas podían traducirse en un comunicado a los padres en los casos de aquellas familias comunistas o en el envío "del planteo" vía una compañera que "lo transmitía", como le sucedió a más de una de las militantes comunistas. En algunos casos la dirección intervenía, en otros los controles eran internos y las propias jóvenes conocían los límites que estaban traspasando si se ennoviaban con quien no pertenecía a la UJC o mucho peor con algún integrante del MLN-T. Que las jóvenes tuvieran novios sin un compromiso de casamiento de por medio había dejado de ser una transgresión a los mandatos de género, sólo que ahora las transgresiones se ubicaban en el terreno de lo político-partidario, como señalaba Laura:

era pro tupa, no sé cómo hice para transgredir aquello, era pro tupa y era del barrio, en el 71 uno iba al comité de base del barrio, a mí me daba un poco de vergüenza decir que tenía un novio tupa, pro tupa, duró unos meses nomás, no lo podía sostener, no se sostenía, lo tenía medio sucuchado, no se sostenía.

Para quienes no eran de familia comunista, el mandato militante de que el novio perteneciera a la UJC, generó dificultades importantes en el seno de la familia. Sin embargo aquellas jóvenes estaban dispuestas a cometer este tipo de transgresiones porque de algún modo la organización las protegía y el novio era parte de un proyecto mayor. Las jóvenes no se ennoviaban, no se acostaban, ni se iban de la casa con "cualquier" novio, sino con alguien con quien "compartían ideales", como explicaba Laura, en la respuesta que ella dio ante un conflicto: "mi madre me relajó toda, fue espantoso, pero yo le dije que «por favor, estamos haciendo la revolución»". El terreno de lo privado quedaba así imbricado con los proyectos públicos que habilitaban o frenaban los novios según su pedigree político, en un contexto de movilización y competencia a la interna de la izquierda donde todo podía ser considerado adverso o beneficioso en una constante campaña de afiliación de los y las nuevas militantes.

Aunque las relaciones sexuales pre-matrimoniales habían sido incorporadas dentro de las pautas de las jóvenes, estas tenían límites: la pareja estable y el amor. El sentimiento amoroso garantizaba la legitimidad a las relaciones sexuales y permitía romper el mandato virginal considerado como una pauta más de la doble moral burguesa. Si bien este discurso pertenecía a la época y recuperaba las consignas más sesentistas de "amor y paz" norteamericanas y europeas, dentro del colectivo comunista funcionaba como una plataforma desde la cual criticar a las familias burguesas. No se explicitaba qué era el amor, pero estaba claro que los códigos marcaban un noviazgo estable para confirmarlo, como señalaba María: "no era transgredir teniendo relaciones sexuales antes de casarse, como mi 
Ana Laura de Giorgi, La otra nueva olaJóvenes mujeres comunistas en el Uruguay de los 60 / The other new wave. Young Communist women in Uruguay 60s, Revista Izquierdas, número 22, enero 2015, ISSN 07185049, Santiago de Chile, pp.204-226

amiga que venía de una familia re católica, eso era una pavadaaaaa, pero todo tenía que ser con amor, sino era con amor, eras un putón del barrio".

Aunque las pautas del noviazgo habían cambiado, esto no implicaba que los novios pudieran pasar la noche juntos con el permiso de los padres. Ninguna de las jóvenes comunistas podía permitirse o le permitían no volver a dormir al hogar. No regresar conducía a un conflicto importante con la familia, específicamente con el padre, y aquella transgresión a los mandatos de género era pagada con una sanción y un insulto en los mismos términos, como recuerda Teresa:

La primera vez que no volví a dormir, mi padre en un ataque, porque ahí si había momentos que regía el pater familia. Al llegar mi madre me dijo: 'tu padre te está esperando', con cara de se pudrió todo y mi padre cuando me ve me dice: 'de donde venís', y yo de la casa de (...) sos una puta, me dijo mi padre.

Un factor señalado como ineludible de la revolución sexual de los sesenta, fue la píldora antinconceptiva, en lenguaje rioplatense: "la pastilla". Este dispositivo de control de la natalidad ha sido mencionado como el aliado indispensable de las relaciones sexuales pre-matrimoniales (Paris y Ruiz (1998:286). En Uruguay la pastilla se sumó como un método más para controlar el número de hijos en la familia ya que la idea de contracepción estaba instalada desde tiempo atrás. Como señala Felitti (2012) para el caso argentino, la pastilla no sólo fue utilizada por mujeres jóvenes sino que sobre todo fue exitosa en aquellas mujeres casadas que no deseaban tener más hijos. La "llegada" de la pastilla a las vidas concretas de las jóvenes no fue sencilla de concretar ya que esta debía ser comprada y tomada a escondidas. Aún en aquellas familias de mayor capital educativo y cultural, la sexualidad era un tema tabú del que no se hablaba en el hogar. Muchas de las jóvenes recuerdan las barreras que había que sortear para llegar finalmente a contar con la pastilla y luego para que padres y hermanos no la descubrieran. La pastilla fue incorporada finalmente, pero esto sucedió principalmente en el marco de una pareja estable o de los matrimonios concretados. Las primeras relaciones sexuales no contaron siempre con la pastilla como aliada y en muchos casos las jóvenes veinteañeras inauguraban su maternidad o transitaron por la experiencia del aborto.

En este punto - maternidad / aborto- la revolución sexual terminaba y comenzaban regir las principales normas de comportamiento aún vigentes en la sociedad y reproducidas por organizaciones políticas que a pesar de propuestas macropolíticas rupturistas, apostaban a no cuestionar la moral vigente. El colectivo comunista promovía ciertas transgresiones, fundamentalmente dentro de los estrictos límites de la militancia, pero fuera de ella tendía a reproducir una moral vigente a la que medianamente bien se acoplaba el partido. Esto sucedía por ejemplo con aquellos temas presentes en la sociedad pero de los que no se hablaba: aborto, homosexualidad, infidelidad y violencia de género.

En Uruguay, el aborto era una práctica más que recurrente e instalada desde principios de siglo. La transición demográfica traducida en un modelo de familia con menos hijos, había contado con el aborto como uno de los métodos corrientes. Como señala Sapriza (1996:132), el reverso del espejo de la maternidad era el aborto, realizado clandestinamente a pesar de ser una práctica corriente. Esto último implicaba que debía realizarse con la mayor discreción y dentro del círculo más cercano de vínculos sociales. 
Ana Laura de Giorgi, La otra nueva olaJóvenes mujeres comunistas en el Uruguay de los 60 / The other new wave. Young Communist women in Uruguay 60s, Revista Izquierdas, número 22, enero 2015, ISSN 07185049, Santiago de Chile, pp.204-226

En el caso del colectivo comunista, esta práctica podía ser realizada por una compañera del partido que fuera enfermera (Sapriza, 1998, 133) o un camarada ginecólogo. Esto no implica que estas situaciones se administraran necesariamente dentro del partido. Probablemente dependía de la capacidad económica para acceder a una clínica privada o a quienes lo realizaban en domicilio en condiciones de riesgo mucho mayores. En todo caso es absolutamente posible pensar que la red de solidaridad que operaba para tantas cuestiones, también podía desplegarse ante estas situaciones. Como sucedía a nivel general, el aborto se administraba entre los vínculos más cercanos y fundamentalmente entre las mujeres. El rol cumplido por algunas madres de la familia comunista que era a quienes recurrían las hijas o las amigas de las hijas en algunos casos era importante. Eran ellas las que se "ocupaban si alguien quedaba embarazada a destiempo", las que iban a hablar con las madres de sus amigas si había "alguna complicación" y las que permitían que otras chicas se quedaran a dormir y recuperarse por unos días ocultando los verdaderos motivos del reposo. En situaciones como estas se actuaba como lo hacía el resto de la sociedad: las jóvenes guardaban el secreto, asumían la situación del aborto sin la compañía del varón y recibían toda la violencia correspondiente: "Claro ir a hacerte un aborto era lo peor, ir a soportar las cosas que te decían, los propios médicos que te trataban como una puta. Ibas a sufrir". La cultura del secreto que aún hoy rodea a este fenómeno, la ética del sacrificio que imperaba en la cultura comunista y el lugar subordinado de lo privado en la agenda política de la época, hacían del aborto una práctica que las jóvenes comunistas, llegado el caso, debían resistir y que no operaba, por más traumática que fuera, como momento de disrupción para cuestionar la desigualdad de género. En este sentido Teresa señalaba:

...la intimidad era un territorio muy complicado ( ...) la cultura dominante era Así se forjó el acero, entonces si uno era duro tenía que serlo, si te hacías un aborto aguantabas, te ibas a la casa de una amiga, te acostabas, ta, y al otro día el tema había desaparecido, no se hablaba más , tampoco existía la psicología ni la terapia, ni las reflexiones filosóficas, las dudas no era un territorio, las dudas las resolvías tu sola.

Muchas jóvenes no quisieron realizarse un aborto o continuar con esta práctica y fueron madres muy jóvenes. En estos casos el dilema estuvo en la temprana edad del embarazo, pero no en la discusión misma sobre la maternidad, como sucedió en la izquierda armada. En el MLN-T, al igual que en otras organizaciones guerrilleras, la maternidad se tornó objeto de discusión entre aquellos que instaban a renunciar a ella en aras de la lucha armada y la vida clandestina, y entre quienes defendían la reproducción como el resultado del amor entre los compañeros y un proyecto político más amplio en el que se precisaban "niños para amanecer" como consignaba la canción de Daniel Viglietti. Dentro de la cultura comunista el mandato biológico fue muy poco cuestionado y como señalaba Susana: "Esas cosas fueron pensadas mucho tiempo después". Un embarazo o un hijo no era un problema mayor en el marco de una militancia legal como podía serlo para una vida clandestina y en este sentido desarmar la idea de que la maternidad era el destino natural de las mujeres fue mucho más complejo, sobre todo porque se realizó en soledad, -entre mujeres- y sin la compañia de los varones. En la izquierda armada y ante las exigencias de la lucha, la renuncia a la maternidad de las mujeres fue definida, por dirigentes varones, como un 
Ana Laura de Giorgi, La otra nueva olaJóvenes mujeres comunistas en el Uruguay de los 60 / The other new wave. Young Communist women in Uruguay 60s, Revista Izquierdas, número 22, enero 2015, ISSN 07185049, Santiago de Chile, pp.204-226

medio necesario para una completa entrega militante. Sin embargo, esta apertura del campo de posibilidades en torno a la reproducción, significó para las mujeres la posibilidad de no ser madres y no ser juzgadas al respecto, así como la contestación a futuro, pasada la lucha armada, del mandato biológico. En las jóvenes comunistas, al igual que en el resto de la sociedad, la opción de no ser madres casi no estaba presente. La idea de la maternidad estaba instalada más acá o más allá en el tiempo porque como recuerda Verónica "tener un bebé era una cosa linda y creo además que todas éramos medio Susanita en aquel tiempo".

Dentro del colectivo comunista, del aborto no se hablaba, pero el parto ocupaba un lugar central ya que las comunistas contaban con el exclusivo "método psicoprofiláctico", aquel que podía permitir controlar el dolor. El método consistía en un procedimiento piscoterapéutico basado en la estimulación verbal. El procedimiento se había comenzado a desarrollar en la URSS en la década del veinte y tuvo su momento de auge en el cincuenta. En Argentina fue difundido a través de Cuadernos de la Cultura y presentado como uno de los casos más exitosos del pavlovismo (García 2012). En Uruguay fue introducido por el médico Hugo Sacchi, quien de forma similar a sus colegas en otros países escribió un libro sobre el parto sin dolor del cual se difundieron sus capítulos en la sección de El Popular para la mujer y el hogar, editado los domingos en el diario del partido. Esta técnica de estimulación verbal más la ética del sacrificio comunista instaban a las mujeres comunistas a sobrellevar el parto no olvidándose de su condición de madres ni de comunistas, como recuerda Margarita respecto al relato de su madre:

Mamá siempre contaba, mi parto fue muy difícil, y contaba que Sacchi le decía: 'sos comunista o que sos', entonces ella se alineaba y aguantaba. Yo me acordaba de eso cuando tuve a mi hija, sos comunista o que sos, dije yo voy a tenerlo a huevo, con el método natural.

Así como no parece haberse discutido el destino biológico tampoco surgieron propuestas de "maternidad socializada" como surgió en la izquierda armada. El sistema de cuidados sería garantizado a futuro en una sociedad en la que la mujer podría contar con servicios públicos en los que se atendieran a los hijos. La imagen era la de la Unión Soviética con sus guarderías y jardines de tiempo completo. La maternidad socializada en todo caso se podía dar a través de un Estado protector, que permitía aliviar la carga sin cuestionar la familia nuclear y el orden patriarcal. Hasta que no se llegara a dicho estadio, las madres debían dividirse entre la crianza y la militancia. En general se daba una clásica división de roles en la que el varón continuaba militando y la mujer quedaba a cargo del hogar. La maternidad parecía en algunos casos ser el fin de aquella emancipación que rechazaba el modelo de mujer tradicional y que las ponía al lado de quien militaba "verdaderamente", como recuerda Laura: "Después lo decíamos sí, es muy fácil ser dirigente si otro te cría los hijos. A ver, yo no lo decía en ese momento porque en ese momento la urgencia de la revolución y yo misma lo justificaba, pero cuando yo quise dar vuelta la tortilla fue difícil, muy muy difícil”.

A pesar de revolución sexual y de ciertas transgresiones a los mandatos de género, el matrimonio continuó siendo una pauta dentro de la cultura comunista y así lo fue para las chicas jóvenes quienes en su mayoría se casaron legalmente. Por un lado las disposiciones 
Ana Laura de Giorgi, La otra nueva olaJóvenes mujeres comunistas en el Uruguay de los 60 / The other new wave. Young Communist women in Uruguay 60s, Revista Izquierdas, número 22, enero 2015, ISSN 07185049, Santiago de Chile, pp.204-226

reglamentarias hacían del matrimonio un mecanismo necesario: las jóvenes que eran menores adquirían la mayoría de edad y si no estaban casadas no podían visitar a sus compañeros presos en la cárcel. Por otra parte, y al igual que la maternidad, el matrimonio no había sido cuestionado radicalmente y la pauta del casamiento continuó reproduciéndose como recuerda Margarita:“...el hoy dice que nos casamos porque eso nos iba a facilitar la vida, yo creo que nos casamos por una cosa de tradición más bien, tradicionalista, y porque hasta ese día dormíamos separados, nos casamos y al otro día pasamos a dormir juntos".

La familia tradicional ocupaba un lugar central en la cultura comunista. El propio partido era considerado una familia y todos sus afiliados sus integrantes. Los dirigentes varones eran quienes estaban al mando y sus mujeres las que acompañaban encargándose de la socialización y educación en el partido. Generaciones enteras nacieron y tuvieron su socialización política dentro de una familia comunista. Se criaron en medio de reuniones políticas y aprendieron a cantar las canciones que otorgaban un sentido de pertenencia y que luego se continuarían cantando generación tras generación. La familia era entonces también estratégica ya que implicaba la reproducción del partido. Los hijos estaban presentes en todos los espacios políticos militando a través de las madres quienes los llevaban a los actos y a las marchas. Esta también era una estrategia no sólo a la interna del partido, sino respecto al mundo exterior, relacionada una vez más a la firme disposición de insertarse en la sociedad y en sus pautas culturales y no en la pretensión de crear una contracultura. La familia heterosexual, patriarcal y nuclear integraba dicho repertorio y la cultura comunista la defendería y promovería ante un fenómeno no menor como era la corriente acusación de que los comunistas enviaban los niños a Moscú.

Como señala Alvarenga (2007), en distintos lugares y tiempos, los partidos comunistas debieron elaborar un discurso que asegurara que el comunismo no era una amenaza para la moralidad instituida sino que esta constituía parte central de su ideario. La cultura comunista uruguaya no quedaría ajena a esta pauta, buscaría en gran parte conservar la moral vigente, reproducir una familia patriarcal, no cuestionar el destino biológico de las mujeres, no denunciar la subordinación de género y no dudar de la "naturaleza" heterosexual. Aquellos temas que pudieran cuestionar el orden instituido y la moral vigente quedarían fuera de la agenda de discusión como recuerda Teresa:

se sabía, pero no se hablaba, había infidelidad claro, así como no se hablaba de la homosexualidad, la manera liberal o moderna escondida, toda esa puja con los valores tradicionales, en teoría no había problema si quedabas embarazada, pero en realidad se armaban unos putos dramas, en teoría te podías hacer un aborto pero nadie decía que se hacia uno.

"Joven, bonita, femenina, pero vigilante, militante..."8

La frase antes citada podría resumir de una forma muy general, la pauta militante de las jóvenes comunistas estudiantes de fines de los sesenta en Uruguay. Como se vio en el

\footnotetext{
${ }^{8}$ Mujeres del Mundo Entero, №3 , 1971, artículo sobre las mujeres jóvenes en Vietnam pp.16
} 
Ana Laura de Giorgi, La otra nueva olaJóvenes mujeres comunistas en el Uruguay de los 60 / The other new wave. Young Communist women in Uruguay 60s, Revista Izquierdas, número 22, enero 2015, ISSN 07185049, Santiago de Chile, pp.204-226

primer apartado, la militancia en la UJC significó para las jóvenes un importante entrenamiento en ciertas aptitudes que se consideraban importantes tanto para participar del convulsionado espacio público como para ascender en la estructura jerárquica de la organización en la que militaban. En este registro, la juventud movilizada parece haber compartido un fenómeno que trascendía a sus sectores políticos de pertenencia, todos querían ser el Che Guevara, tanto dentro de la izquierda armada como de la legal, tanto los varones como las mujeres. La juventud compartió la calle y tomó distancia de las generaciones precedentes. Sin dudas la ruptura realizada por las jóvenes fue mucho mayor que la de los jóvenes. La violencia cotidiana y la movilización callejera les demandó a las jóvenes un esfuerzo en términos de valentía, sacrificio y resistencia que las alejaba de ciertas pautas de femineidad vigentes y que les permitió distanciarse de lo que habían sido las trayectorias de sus madres, fundamentalmente en el caso de aquellas que inauguraban en su familia el ingreso a lo político. El rol emancipador de la militancia fue fundamental para aquellas jóvenes que se distanciaron de sus tradiciones familiares y aprendieron como dicen ellas a "tener ideas propias".

Quienes provenían de una familia comunista tuvieron la oportunidad de contar con una temprana socialización política que había introducido el mundo de lo público en el hogar. En estos casos, las jóvenes fueron más continuadoras de las trayectorias de sus madres en el sentido que estas últimas, aún dentro de una familia patriarcal, habían logrado ciertos márgenes para contar con voz y voto. La transgresión a los mandatos de género no provino en estos casos de una inmersión en el mundo de la política sino de la interpelación de la revolución cultural y sexual que les permitió tener mayores márgenes de libertad en el terreno de lo que se consideraba "privado". La preeminencia de lo político no permitía la discusión de cuestiones que se consideraban poco importantes como la moda, los bailes, la música y las relaciones personales (y sexuales), y de alguna manera su no tematización habilitaba participar de todo aquello. Esto era posible si lo político estaba asegurado, es decir, mientras fueran buenas hijas de la familia comunista, buenas militantes, podían dentro de ciertos límites disfrutar de la nueva ola, ir a los bailes, vestirse a la moda, ir de campamento con varones, mantener relaciones sexuales pre-matrimoniales, casarse y divorciarse más de una vez.

En cualquier caso el disfrute o participación de la movida que definió una particular cultura juvenil y las posibilidades de disfrutar de la revolución sexual, para el caso de las jóvenes comunistas, dependió mucho más de una pertenencia de clase que de la tradición política familiar. Se requerían recursos materiales, culturales y simbólicos para comprar ropa a la moda, bailar rock and roll en las boites, cantar -en inglés- la música beat, desafiar al padre con la minifalda, ir a la farmacia a comprar la pastilla o estar dispuestas a no regresar a dormir al hogar paterno. Esto fue posible por la pertenencia de clase y por la posibilidad de experimentar lo que la clase habilitaba. Las trayectorias diferenciadas de las jóvenes comunistas estuvieron marcada por cierta habilitación a esa diferencia que les permitió a la vez que comunicarse intra-clase con el resto de la sociedad, reproducir la diferenciación a la interna del colectivo. A diferencia de la cultura tupamara en la que primó una pauta homogeneizadora que orientaba al "suicido de clase", al decir del extupamaro Zabalza, y la cultura del pobrismo (de Giorgi, 2011), en el colectivo comunista la diferenciación material y cultural no fue intervenida y esto se tradujo en distintas configuraciones de la experiencia militante. 
El análisis de la experiencia de las jóvenes estudiantes comunistas de fines de los sesenta, nos conduce a visualizar un recorrido que toma distancia de la imagen de la mujer guerrillera con la cual suele pensarse a las militantes de izquierda de los sesenta en el Conosur así como a revisar la imagen de los y las comunistas como aislados del entorno y encerrados en un partido foráneo con ojos solo para la URSS. Las jóvenes comunistas estudiantes vivieron el 68 uruguayo con todo lo que ello implicaba, con molotovs y música beat (Markarian, 2012), con minifalda y pastilla anticonceptiva.

Esto último delineó distintos caminos para transgredir los mandatos de género vigentes, vía revolución política o vía revolución cultural y sexual. Esta distinción analítica probablemente es arbitraria, pero se torna pertinente en la medida que las transgresiones fueron de distinto signo. La revolución política implicó la inmersión en un espacio público habitado por varones y la incorporación de pautas de una militancia regida por lo masculino en donde el extremo de la entrega se medía por la renuncia al símbolo inequívoco de la femineidad vigente: la maternidad. Por su parte la revolución cultural y sexual de algún modo reforzó la femineidad vigente: las jóvenes usaron bikinis, minifaldas, vestidos, pelo largo, dispusieron de la pastilla y decidieron, (entre los hombres) con quien mantener relaciones sexuales. La revolución sexual fue, además de discreta, heterosexual e interpeló directamente a las mujer liberándola de algunos mandatos pero reinscribiéndola en tanto mujer y reproduciendo como naturalizado la división de lo femenino y lo masculino.

Si la hipótesis anterior es acertada, se instala la interrogante para futuras investigaciones, sobre los distintos derroteros de las jóvenes del 68 en sus concepciones sobre la emancipación de la mujer llegados los ochenta y la segunda ola del feminismo en Uruguay. La homogeneización en clave masculina ifue lo que permitió tomar distancia de las pautas de la feminidad vigentes y contestarlas a futuro? La re-feminización ise constituyó como un elemento importante para visibilizar a la mujer y contestar el patriarcado desde la diferencia?

Recibido: 5 septiembre 2014

Aceptado: 2 diciembre 2014

\section{Bibliografía}

Achugar, Hugo (1998): "Paisajes y escenarios de la vida privada, literatura uruguaya entre 1920 y 1990", Historias de la vida privada en el Uruguay. Individuo y soledades 19201990, Tomo III, Taurus, Montevideo.

Aldrighi, Clara (2009): Memorias de insurgencia. Historias de vida y militancia en el MLN-Tupamaros. 1965-1975, Ediciones de la Banda Oriental, Montevideo.

Alvarenga Patricia (2007): "Sexualidad y participación política femenina en la izquierda costarricense”, en Inter.c.a.mbio, año 4, na 5, pp. 231-267 
Andújar, Andrea et al (2005): Historia, género y política en los 70, Libro virtual, coeditado con Feminaria Editora, Buenos Aires. http://www.feminaria.com.ar

Andújar Andrea et al (2009): De minifaldas, militancias y revoluciones. Exploraciones sobre los 70 en la Argentina, Ediciones Luxemburg, Buenos Aires.

Barrancos, 2008, Mujeres, entre la casa y la plaza. Buenos Aires: Sudamericana. Cabella Wanda (1999): "La evolución del divorcio en el Uruguay (1950-1995)", Documento de trabajo $N^{\circ}$ 43, Unidad Multidisciplinaria, Facultad de Ciencias Sociales, Universidad de la República, Montevideo.

Cernadas J.,Pittaluga R. y Tarcus H. (1997): "Para una historia de la izquierda en la Argentina. Reflexiones preliminares", El Rodaballo. Revista de política y cultura,n 6/7, Buenos Aires, otoño-invierno de 1997, pp. 28-35.

Cosse, Isabella et al (2010): Los 60 de otra manera. Vida cotidiana, género y sexualidades en la Argentina, Prometeo Libros, Buenos Aires

Cosse, Isabella (2010): Pareja, sexualidad y familia en los años sesenta. Siglo XXI Editores, Buenos Aires.

de Giorgi, Ana Laura (2011): Las tribus de la izquierda: bolches, latas y tupas en los 60, Editorial Fin de Siglo, Montevideo

de Giorgi, Ana Laura (2013): "Mucho más que foco o partido: las militancias de comunistas y tupamaros durante los 60 en Uruguay”, Revista de Antropología y Sociología: Virajes Vol 15-1.

Diana, Marta (2006): Mujeres guerrilleras, Planeta, Buenos Aires; Martínez, Paola (2009): Género, política y revolución en los años setenta. Las mujeres del PRT-ERP, Editorial Imago Mundi, Buenos Aires.

Felitti , Karina (2012): La revolución de la píldora. Sexualidad y política en los sesenta, Edhasa, Buenos Aires.

Garcé, Adolfo (2006): Donde hubo fuego. El proceso de adaptación del MLN-Tupamaros a la legalidad y a la competencia electoral (1985 - 2004), Editorial Fin de Siglo, Montevideo

García Luciano (2012): La recepción de la psicología soviética en la Argentina: lecturas y apropiaciones en la psicología, psiquiatría y psicoanálisis (1936-1991), Tesis Doctoral, Facultad de Filosofía y Letras, Universidad de Buenos Aires (UBA), Buenos Aires.

Graña, François (2011): Los padres de Mariana: María Emilia Islas y Jorge Zaffaroni: la pasión militante 
Greising Carolina (....): "La educación uruguaya, 1960-1984”, Medio siglo de historia uruguaya, Banda Oriental, Montevideo.

Labrousse Alain (2009): Una historia de los tupamaros. De Sendic a Mujica, Editorial Fin de Siglo, Montevideo

Lessa Alfonso (2002): La revolución imposible, Editorial Fin de Siglo, Montevideo

Leibner Gerardo (2010): Camaradas y compañeros. Una historia política y social de los comunistas del Uruguay, Ediciones Trilce, Montevideo

Leibner, Gerardo (2004): "Nosotras (Uruguay, 1945-1953): Las contradicciones de la escritura femenina comunista y sus significados sociales", en Roland Forgues y JeanMarie Flores, editores, Escritura femenina y reivindicación de género en América Latina, Mare \& Martin, París.

Manzano, Valeria (2010): "Juventud y modernización sociocultural en la Argentina de los sesenta”, Desarrollo Económico, Vol.50, №199, pp.363-390

Markarian, Vania (2012): El 68 uruguayo. El movimiento estudiantil entre molotovs y música beat, Universidad Nacional de Quilmes Editorial, Bernal.

Markarian, Vania (1998): "Al ritmo del reloj: adolescentes uruguayos de los años cincuenta", Historias de la vida privada en el Uruguay. Individuo y soledades 1920-1990, Tomo III, Taurus, Montevideo.

Martínez Paola (2009): Género, política y revolución en los años sesenta. Las mujeres del PRT-ERP, Editorial Imago Mundi, Buenos Aires.

Paris J., Ruiz E. (1998): "Ser militante en los sesenta", Historias de la vida privada en el Uruguay III. Individuo y soledades 1920-1990, Taurus, Montevideo.

Rey Tristán, Eduardo (2006): A la vuelta de la esquina. La izquierda revolucionaria uruguaya. 1955-1973, Editorial Fin de Siglo, Montevideo.

Rodríguez V., Sapriza G. (1984): Mujer, Estado y Política en el Uruguay del Siglo XXI, Ediciones de la Banda Oriental, Montevideo.

Sapriza, Graciela (...): "Mentiras y silencios: el aborto en el Uruguay del novecientos", Historias de la vida privada en el Uruguay. El nacimiento de la intimidad 1870-1920, Tomo II, Taurus, Montevideo 
Sempol, Diego (2010): "Homosexualidad y cárceles políticas uruguayas.La homofobia como política de resistencia", Sexualidad, Salud y Sociedad, Revista Latinoamericana, №4, www.sexualidadsaludysociedad.org.

Silva, Marisa (2009): Aquellos comunistas (1955-1973), Editorial Taurus, Montevideo

Valobra I. (2010): Del hogar a las urnas. recorridos de la ciudadanía política femenina Argentina, 1946-1955, Prohistoria, Buenos Aires

Valobra I. (2007): "Radicales y comunistas en pro de los derechos políticos de las mujeres 1946-1955, en Barr C. (Comp.) El Sufragio femenino en América Latina, UNTREF, Argentina.

Valobra I. (2005): "La UMA en marcha. Tradiciones y estrategias de movilización social en los partidos opositores durante el peronismo. El caso del Partido Comunista y la Unión de Mujeres de la Argentina", Canadian Journal of Latin American and Caribbean Studies, Vol. 30, N.60, 155-183. 